\title{
STRATEGI KOMUNIKASI INTERNAL DALAM \\ MENUMBUHKAN LOYALITAS KARYAWAN PT \\ PRUDENTIAL LIFE ASSURANCE (STUDI DESKRIPTIF PADA \\ PRU ETERNITY KOTA CILEGON)
}

\author{
Isniyunisyafna, S.Ikom, M.Si \\ Dea Sarah Isfiantie $\mathbf{S}$ \\ Email : isni@unis.ac.id \\ Program Studi Ilmu Komunikasi, Fakultas Ilmu Sosial Ilmu Politik \\ Universitas Islam Syekh-Yusuf Tangerang
}

\begin{abstract}
ABSTRAK
Penelitian ini bertujuan untuk menggambarkan bagaimana pelaksanaan strategi komunikasi internal PRU Eternity dalam menumbuhkan loyalitas karyawan. Penelitian ini dilakukan dengan menggunakan pendekatan kualitatif, yang bersifat deskriptif dan Teori Hubungan Manusia. Metode pengumpulan data dilakukan dengan menggunakan metode wawancara mendalam dan observasi. Hasil penelitian mengungkapkan bahwa strategi komunikasi internal yang dilakukan oleh AM (Agency Manager) adalah dengan mengadakan berbagai forum komunikasi melalui konsep Perencanaan, Implementasi dan Evaluasi. kegiatan komunikasi dilakukan secara tatap muka melalui forum yang diadakan rutin sesuai dengan jadwalnya masing-masing. Interaksi yang terjadi didalam forum tersebut menumbuhkan rasa kebersamaan karyawan serta loyalitas dari diri karyawan tersebut.
\end{abstract}

Kata kunci : Strategi Komunikasi Internal, Public Relations, Loyalitas

\begin{abstract}
The purpose of this research to describe internal communication strategy of PRU Eternity in growing employee loyalty. This research using qualitative approach method, a descriptive character with Relations Human Theory. Depth conversation and observation methods are using for this research. The result from this research shows the internal communications strategy of AM (Agency Manager) by holding various communication forums through the concepts of planning, implementation and evaluation. Communication activities are carried out face-to-face through a forum that is held routinely according to their
\end{abstract}


respective schedules. Interaction that happened during the forum rising up togetherness between employees and loyalty from the employee themselves.

Key word $\quad$ : Internal Communication Strategy, Public Relations, Loyalty

\section{PENDAHULUAN}

Peningkatan

terhadap

penggunaan jasa asuransi dari tahun

ke tahun telah menjadi perhatian di kalangan masyarakat. Sejalan dengan perkembangan dunia usaha yang dinamis dan kompetitif, bisnis jasa asuransi membutuhkan berbagai perangkat untuk bisa meningkatkan daya saingnya. Salah satu perangkat yang bernilai tinggi dan memberikan nilai tambah adalah melalui penerapan Good Corporate Governance (GCG). Perusahanperusahaan yang menjalankan GCG secara baik dan berkelanjutan memiliki nilai lebih bila dibandingkan dengan perusahaanperusahaan yang belum menerapkan GCG. Untuk mewujudkan perusahaan yang tumbuh berkembang dan berdaya saing tinggi, PT. Prudential Life Assurance telah mengembangkan struktur dan system tata kelola perusahaan (Good Corporate Governance) dengan memperhatikan prinsip-prinsip GCG sesuai ketentuan dan peraturan serta best practise yang berlaku. Komitmen penerapan GCG merupakan hal yang mutlak bagi Prudential. Mekanisme yang telah dijalankan dalam penerapan GCG ini dilakukan untuk mengatur dan mempertegas kembali hubungan, wewenang, peran dan tanggung jawab didalam perusahaan yang bertujuan meningkatkan kinerja karyawan, menciptakan nilai tambah bagi semua pemangku kepentingan, serta mencegah dan mengurangi manipulasi atau kesalahan dalam mengelola organisasi. Oleh karena itu loyalitas karyawan berpengaruh terhadap system tata kelola GCG, dimana jika loyalitas karyawan baik maka kinerja karyawan terhadap perusahaan juga akan baik. Diperlukan sikap loyalitas dari para anggota dalam menjalankan sebuah organisasi agar dapat mencapai tujuan bersama. Namun dalam $P R U$ Eternity Kota Cilegon PT. Prudential Assurance masih banyak tantangan untuk membangun loyalitas. Pertama, dalam pemaknaan loyalitas, kurangnya sikap pengertian dari setiap anggota bagaimana seharusnya mereka melakukan tugasnya dalam organisasi. Kedua, penerapan dalam menciptakan GCG ini juga belum sepenuhnya dipatuhi oleh seluruh karyawan sehingga diperlukannya strategi komunikasi internal yang dapat menumbuhkan loyalitas dari diri karyawan tersebut. Arah dan tujuan organsisasi hanya ditentukan oleh pihak manajemen sebagai pemimpin. Sehingga segala macam bentuk kebijakan perusahaan 
merupakan keputusan dari pihak manajemen saja. Karyawan tidak banyak mengambil bagian dari proses pengambilan keputusan, bahkan tidak dilibatkan sama sekali. Sehingga ketika yang terjadi adalah kesalahan pengambilan keputusan, maka yang terjadi adalah ketidakadilan bagi diri karyawan, karena mereka sebagai pihak yang tidak dilibatkan namun mendapat dampak negatif dari kesalahan pengambilan keputusan tersebut. Disinilah akar hubungan yang tidak baik dengan karyawan dapat terjadi. Tidak heran muncul banyak masalah terkait ketenagakerjaan. Untuk mencegah kondisi seperti itu, diperlukan sebuah strategi agar tercipta hubungan yang harmonis antara perusahaan dengan karyawan. Perusahaan mulai menyadari pentingnya pembinaan hubungan yang baik dengan karyawan dalam upayanya mencapai tujuan perusahaan. Karyawan tidak hanya ditempatkan sebagai pelaku bagi pendukung aktifitas perusahaan saja, namun juga sudah dilibatkan dalam setiap pengambilan keputusan yang menyangkut masa depan perusahan. Karyawan sudah diberikan haknya untuk memberikan suara terhadap setiap hal yang berkaitan dengan perusahaan. Oleh karena itu dalam penelitian ini peneliti ingin mengetahui bagaimana strategi komunikasi internal yang dilakukan oleh divisi humas (agency manager) dengan karyawan PRU Eternity PT.
Prudential Life Assurance Kota Cilegon dan bagaimana peran PR (agency manager) dalam menumbuhkan loyalitas karyawan PRU Eternity PT. Prudential Life Assurance Kota Cilegon

\section{TINJAUAN PUSTAKA}

\section{A. LANDASAN TEORI}

\section{Teori Hubungan Manusia Elton Mayo}

Teori yang peneliti gunakan adalah "Teori Hubungan Manusia yang diperkenalkan pada tahun 1930-an yang dipelopori oleh Mayo (1933), Bernard (1938), Roethlishetger dan Dicshon (1939). Teori hubungan manusia ini merupakan teori yang mengkaji aspek psikologis dan humanis yang berorientasi pada hubungan manusia sebagai makhluk sosial. Adapun yang ditekankan dalam teori ini adalah pentingnya individu dan hubungan sosial dalam kehidupan organisasi" (Arni, 2014:40). Asumsi dari teori ini adalah pengaruh komunikasi manusia terhadap interaksi atau tingkah laku anggota organisasi terhadap kinerja dan pengaruh positif, serta adanya norma-norma sosial bagi anggota organisasi. Ada tiga implikasi kunci dari studi ini yang tampaknya memberikan dasar bagi pengembangan teori hubungan manusia, sebagai suatu perspektif pilihan terhadap teori klasik untuk mempelajari 
organisasi maupun mempelajari komunikasi organisasi. Adapun ketiga implikasi tersebut adalah sebagai berikut:

1. Dalam produksi kerja menunjukkan proses komunikasi manusia terhadap perilaku anggota organisasi. Pada implikasinya bahwa pekerja selalu melalui komunikasi, menjadi bagian yang amat penting pada bidang komunikasi organisasi.

2. Pengaruh yang positif dari wawancara kepada pekerja yang mengarahkan kepada identifikasi mengenai komunikasi upward atau komunikasi dari bawah kepada atasan dan sebaliknya, dari karyawan kepada atasan sebagai aktivitas organisasi yang berguna.

3. Penemuan norma-norma sosial bagi karyawan mengarahkan identifikasi mengenai adanya pengaruh channel informal dari komunikasi pada anggota organisasi. Teori hubungan manusia mulai melihat kepada komunikasi informal melalui garis sosial dari komunikasi organisasi." (Arni, 2014:42-43)

\section{KOMUNIKASI}

"Istilah komunikasi berasal dari kata Latin communicatio, dan bersumber dari kata communis yang berarti sama. Sama disini maksudnya adalah satu makna. Jadi, jika dua orang terlibat dalam proses komunikasi, maka proses komunikasi akan berlangsung selama ada kesamaan makna mengenai apa yang dikomunikasikan, yakni baik si penerima maupun si pengirim memiliki pemahaman yang sama dari suatu pesan tertentu" (Effendy, 2011:9). "cara terbaik untuk menjelaskan bagaimana kegiatan komunikasi adalah menjawab pertanyaan Who Say What in Which Channel To Whom What Effect (Siapa Mengatakan apa Melalui Saluran apa Kepada Siapa Dengan Efek apa). Paradigma Laswell menunjukkan bahwa komunikasi meliputi lima unsur,yakni:Communicator(Kom unikator), Message (Pesan), Media (Media), Receiver (Komunikan atau penerima), dan Effect

(Efek)"(Effendy,2007:253).

\section{STRATEGI KOMUNIKASI}

"Anwar Arifin menyatakan bahwa sesungguhnya suatu strategi adalah keseluruhan keputusan kondisional tentang tindakan yang akan dijalankan untuk mencapai tujuan. Jadi, merumuskan strategi komunikasi berarti memperhitungkan kondisi dan situasi (ruang dan waktu) yang 
terjadi dan yang mungkin akan terjadi di masa depan untuk mencapai efektifitas.

Dengan strategi komunikasi ini dapat ditempuh beberapa cara memakai komunikasi dengan baik untuk menciptakan perubahan pada diri khalayak dengan mudah dan cepat" (Suryadi, 2018:5-6)

\section{KOMUNIKASI INTERNAL}

Menurut Muslim Basya dan Irmulan Sati "komunikasi internal adalah komunikasi antara manajer dengan komunikan (khalayak atau karyawan dari mulai level top management, middle management, dan lower management) yang berada didalam organisasi, secara timbal balik. Karena dalam organisasi terdapat jenjang kepangkatan yang menyebabkan adanya pegawai yang memimpin dan pegawai yang dipimpin, maka dalam manajemen tidak saja terjadi komunikasi antar pegawai yang sama status atau pangkatnya". (Oktavia, 2014:26)

5. KOMUNIKASI ORGANISASI

"Definisi komunikasi organisasi menurut R Wayne Pace Don F. Faules dalam bukunya yang berjudul Komunikasi Organisasi (strategi meningkatkan kinerja perusahaan) 2006 adalah perilaku pengorganisasian yang terjadi dan bagaimana mereka yang terlibat dalam proses itu bertansaksi dan memberi makna atas apa yang sedang terjadi."

\section{PUBLIC RELATION}

"menurut Rex Harlow dalam

(Rosadi Ruslan 2013:16)

menyatakan bahwa "Public

Relations adalah fungsi

menejemen yang khas dan

mendukung pembinaan,

pemeliharaan jalur bersama antara organisasi dengan publiknya, menyangkut aktifitas komunikasi, pengertian, penerimaan dan kerjasama; melibatkan menejemen dalam menghadapi persoalan-persoalan, mebantu menejemen mampu menanggapi opini publik; mendukung menejemen dalam mengikuti dan memanfaatkan perubahan secara efektif; bertindak sebagai sistem peringatan dini dalam mengantisipasi kecenderungan pengunaan penelitian serta teknik komunikasi yang sehat dan etis sebagai sarana utama".

"Menurut Cutlip, Center \& Broom dalam kutipan Rachmat Kriyantono (Kriyantono, 2008:5) public relations adalah fungsi manajemen yang membangun dan mempertahankan hubungan yang baik dan bermanfaat antara organisasi dengan publik yang mempengaruhi kesuksesan atau kegagalan organisasi tersebut."

7. CORPORATE COMMUNICATION 
"Menurut buku Essentials

Corporate Communication oleh

Cees van Riel dan Charles

Fombrun

Corporate

Communication dapat

didefinisikan sebagai serangkaian

kegiatan yang termasuk dalam

pengelolaan dan pengaturan

segala komunikasi internal dan

eksternal yang ditujukan untuk menciptakan titik awal yang menguntungkan dengan para pemilik kepentingan, tempat di mana perusahaan bergantung. Komunikasi perusahaan terdiridari penyebaran informasi oleh sebuah divisi ahli dalam sebuah organisasi, dengan tujuan umum meningkatkan kemampuan organisasi untuk mempertahankan lisensi untuk beroperasi”. (Ramdan, 2017:13)

\section{LOYALITAS}

Hasibuan mengemukakan bahwa "loyalitas atau kesetiaan merupakan salah satu unsur yang digunakan dalam penilaian karyawan yang mencakup kesetiaan terhadap pekerjaannya, jabatannya dan organisasi. Kesetiaan ini dicerminkan oleh kesediaan karyawan menjaga dan membela organisasi didalam maupun diluar pekerjaan dari rongrongan orang yang tidak bertanggung jawab" (Sujiyanto 2017:66).

Loyalitas menurut Griffin (2002) dalam (Hurriyati, 2010:128) menyatakan bahwa "loyality is defined as non random purchase expressed over time by some decision making unit". Berdasarkan definisi tersebut terlihat bahwa loyalitas lebih ditunjukan kepada suatu perilaku, yang ditunjukan dengan pembelian rutin, didasarkan pada unit pengambilan keputusan."

\section{METODOLOGI PENELITIAN}

Metode penelitian ini menggunakan metode kualitatif. Sugiyono (2017:9) berpendapat bahwa "metode penelitian yang berlandaskan filsafat postpositivisme, digunakan untuk meneliti pada kondisi obyek yang alamiah, artinya data yang dikumpulkan bukan berupa angkaangka, melainkan data tersebut berasal dari naskah wawancara, catatan lapangan, dokumen pribadi, serta dokumen resmi lainnya. Sehingga yang menjadi tujuan dari penelitian kualitatif ini adalah ingin menggambarkan realita empirik dibalik fenomena secara mendalam, rinci dan tuntas".

Paradigma konstruktivisme memandang bahwa "kenyataan itu hasil konstruksi atau bentukan dari manusia itu sendiri. Kenyataan itu bersifat ganda, dapat dibentuk, dan merupakan satu keutuhan. Kenyataan ada sebagai hasil bentukan dari kemampuan berpikir seseorang. Pengetahuan hasil bentukan manusia itu tidak bersifat tetap tetapi 
berkembang secara terus-menerus. Pengenalan manusia terhadap realitas sosial berpusat pada subjek dan bukan pada objek, hal ini berarti bahwa ilmu pengetahuan bukan hasil pengalaman semata, tetapi merupakan juga hasil konstruksi oleh pemikiran" (Arifin, 2012).

Tradisi penelitian ini adalah deskriptif kualitatif. Tradisi deskriptif kualitatif adalah salah satu tradisi penelitian yang banyak digunakan pada penelitian yang bertujuan untuk menjelaskan suatu kejadian. Seperti yang dikemukakan oleh Sugiyono (2011) "penelitian desktiptif adalah sebuah penelitian yang bertujuan untuk memberikan atau menjabarkan suatu keadaan atau fenomena yang terjadi saat ini dengan menggunakan prosedur ilmiah untuk menjawab masalah secara aktual". Sukmadinata (2016) menyatakan bahwa "penelitian deskriptif adalah sebuah penelitian yang berusaha mendeskripsikan, menginterpretasikan sesuatu, misalnya kondisi atau hubungan yang ada, pendapat yang berkembang, proses yang sedang berlangsung, akibat atau efek yang terjadi atau tentang kecenderungan yang sedang berlangsung". Dari kedua pengertian tersebut, dapat dikatakan bahwa tradisi penelitian deskriptif adalah sebuah tradisi yang digunakan untuk mendeskripsikan, menginterpretasikan sesuatu fenomena, dengan menggunakan prosedur ilmiah untuk menjawab masalah secara aktual.

\section{PEMBAHASAN}

\section{Strategi Komunikasi Internal PRU Eternity PT Prudential Life Assurance}

Strategi komunikasi yang dilakukan PRU Eternity dalam menumbuhkan loyalitas para karyawannya adalah dengan berbagai program yang diharapkan dapat merubah tingkat loyalitas dari karyawan tersebut. Adapun strategi yang dilakukan oleh agency manager dalam menumbuhkan loyalitas karyawan meliputi:

\section{a) Analisa/Perencanaan \\ Strategi (Planning)}

Analisa perencanaan yang digunakan PRU Eternity untuk menentukan perencanaan strategi tersebut tentu melihat kendalakendala yang ada dilapangan terkait demografi, minat daya beli masyarakat dan lebih fokusnya kepada market dan competitor.

Bagi public relations yang paling mendasari dari perencanaan program adalah tujuan perusahaan. Perencanaan program setiap waktu bisa berubah tergantung realita kondisi lapangan. Salah satu proses dalam perencanaan ini adalah mengenal khalayak 
sasaran dari strategi komunikasi internal yang dibuat. Khalayak sasaran yang dimaksud disini adalah karyawan. Dimana strategi komunikasi dibuat sematamata untuk kesejahteraan perusahaan, perusahaan tentu menginginkan semua karyawannya bekerja dengan sepenuh hati agar tercapai tujuan perusahaan, maka dari itu dibuat strategi komunikasi internal, dimana dalam penerapannya berpengaruh terhadap loyalitas karyawan

b) Implementasi Strategi (Implementation)

Pada PRU Eternity, tahap implementasi strateginya terbilang cukup baik dengan total presentase $75 \%$ dari pencatatan di bulan mei, artinya penerapan strategi didalam tim sudah cukup berhasil. Implementasi yang dilakukan oleh PR (Agency Manager) PRU Eternity antara lain membuat berbagai program kegiatan seperti: FM3 (Fun Monday Morning Motivation), Enganggement team (Target persistensi triwulan), Forum training dan motivations serta Discussion session full team.

c) Evaluasi Strategi
Dalam PRU Eternity evaluasi biasa dilakukan setiap bulan dan melibatkan masing-masing direct perarea. Evaluasi dilakukan dari founder ke direct sales (agency manager) dari setiap area. Untuk mengetahui apakah program yang disusun berhasil atau tidak, AM melakukan evaluasi dengan melihat seberapa antusias karyawan dalam mensejahterakan

perusahaannya dan apakah sejauh ini strategi yang telah dibuat berhasil dalam menumbuhkan loyalitas para karyawan. Hasil dari evaluasi tersebut nantinya akan dikembangkan lagi dengan berbagai inovasi yang menarik agar dapat mencapai tujuan bersama.

\section{Public Relations (Agency Manager) PRU Eternity PT Prudential Life Assurance}

Dalam PRU Eternity PT. Prudential Life Assurance, Public relations dibantu oleh karyawan dan agen, public relations disini bertugas mengelola sistem pemasaran internal dan eksternal perusahaan, karena PR dan Agen sama-sama berperan penting dalam sistem pemasarannya.

Silih Agung (2005) menyatakan "PR bersinergi dengan divisi SDM untuk 


\begin{tabular}{lrr} 
mengatasi & masalah & seperti \\
bagaimana & \multicolumn{2}{r}{ meningkatkan } \\
loyalitas karyawan. & Karena \\
loyalitas karyawan hanya sebatas & pada loyalitas profesi, & bukan \\
pada & loyalitas pada perusahaan”. Pada \\
sisi ini AM & membantu & SDM \\
dalam membangun & sistem \\
komunikasi & internal & yang \\
memungkinkan & semua & pihak \\
mendapatkan & akses & untuk \\
menyuarakan & pendapatnya.
\end{tabular}

Sistem komunikasi dua arah yang mampu mewakili aspirasi manajemen dan karyawan. Akses secara perlahan membangun loyalitas karyawan terhadap perusahaan itu sendiri.

Peran public relations sebagai leader memberi pengarahan kepada agent agar menjadi agent yang baik bagi calon nasabahnya. Yang dilakukan PR biasanya membuat sebuah kegiatan beberapa training untuk karyawannya dengan menebarkan nilai positif, melatih karyawannya untuk saling menghormati dan menhargai satu dengan lainnya, mejelaskan prosedur tentang bagaimana berasuransi, serta memberikan motivasi-motivasi dari ahlinya untuk mencapai target yang diinginkan dan tentunya akan di bimbing sampai sukses.

\section{Loyalitas Karyawan}

Dalam menumbuhkan loyalitas tentunya AM PRU
Eternity mempunyai cara tersendiri, seperti yang sudah dibahas diatas bahwa strategi yang dilakukan ialah membuat forum komunikasi, dimana jika dalam forum tersebut karyawan bisa menembus target yang diharapkan bukan tidak mungkin ia akan mendapat imbalan seperti gathering ke luar kota bahkan luar negri.

Loyalitas kerja karyawan tidak terbentuk begitu saja dalam organisasi, tetapi ada indikator yang terdapat didalamnya yang mewujudkan loyalitas kerja karyawan. Masing-masing indikator merupakan bagian dari manajemen yang berkaitan dengan karyawan maupun organisasi. Dari indikator yang telah dijelaskan, yang terlihat dalam PRU Eternity cukup baik, para karyawan selalu menaati setiap kebijakan peraturan yang berlaku, memiliki tanggung jawab melaksanakan tugas, memiliki kemauan untuk bekerjasama didalam tim, memiliki hubungan yang baik dengan manajemen perusahaan, serta menyukai pekerjaan yang dilakukan.

Oliver memberikan empat tahapan proses pembentukan loyalitas yaitu:

a. Cognitive Loyalty (kesetiaan berdasarkan kesadaran)

b. Affective Loyalty (kesetiaan berdasarkan pengaruh) 
c. Conative Loyalty (kesetiaan berdasarkan komitmen)

d. Action Loyalty (Kesetiaan dalam bentuk tindakan)

Dari keempat proses pembentukan loyalitas, terlihat bahwa karyawan PRU Eternity sudah cukup baik dalam pembentukan loyalitas, dalam hal Cognitive Loyalty, informasi yang diberikan oleh direct agent kepada karyawan cukup memuaskan, hal itu berdampak pada kesadaran para karyawannya, dalam hal Affective Loyalty, pengaruh yang diberikan lewat motivasi secara tidak langsung mempengaruhi loyalitas dari diri karyawan tersebut. Kondisi ini sangat sulit dihilangkan karena loyalitas sudah ada dalam pikiran para karyawan bukan hanya kesadaran. Dalam hal Conative Loyalty, dirasa belum cukup berhasil sepenuhnya, karena hasrat untuk melakukan suatu tindakan atau bersikap loyal belum sepenuhnya dijalankan oleh para karyawan dan dalam hal Action Loyalty, tindakan yang dilakukan oleh para karyawan dinilai sudah cukup baik walaupun tidak sepenuhnya mematuhi atau bersikap loyal terhadap pekerjaannya.

\section{KESIMPULAN}

Berdasarkan penelitian yang telah dilakukan mengenai strategi komunikasi internal dalam menumbuhkan loyalitas karyawan PRU Eternity PT Prudential Life Assurance, maka diperoleh kesimpulan sebagai berikut:

1. Strategi komunikasi yang dilakukan PRU Eternity dalam menumbuhkan loyalitas para karyawannya adalah dengan mengadakan berbagai forum komunikasi. Adapun strategi yang dilakukan oleh agency manager dalam menumbuhkan loyalitas karyawan meliputi:

- Analisa perencanaan strategi (Strategic

Planning), PRU Eternity Prudential memiliki keputusan membuat strategi dan tujuan untuk membangun dan memelihara hubungan dengan karyawan, memiliki khalayak penentu yaitu karyawan, memiliki program-program yang memudahkan nasabah, melakukan kegiatan sesuai dengan prosedur yang berlaku dari perusahaan, dan public relations menjalankan program tersebut.

- Implementasi Strategi, Pada PRU Eternity, tahap implementasi strateginya terbilang cukup berhasil dengan total presentase $75 \%$ dari pencatatan di bulan mei, implementasi yang 
dilakukan oleh PR (Agency

Manager) PRU Eternity antara lain membuat berbagai program kegiatan seperti: FM3 (Fun Monday Morning Motivation), Enganggement team (Target persistensi triwulan), Forum training dan motivations serta Discussion session full team.

- Evaluasi

Strategi

(Evaluation), Dalam PRU

Eternity evaluasi dilakukan melihat seberapa besar target salesnya, biasa dilakukan setiap bulan dan melibatkan masing-masing direct per-area. Evaluasi dilakukan dari founder ke direct sales (agency manager) dari setiap area.

2. Peran PR (Agency Manager) dalam menumbuhkan loyalitas karyawan, dalam PRU Eternity peran public relations sebagai leader memberi pengarahan kepada agent agar menjadi agent yang baik bagi calon nasabahnya. Yang dilakukan AM biasanya membuat sebuah kegiatan didalam forum komunikasi seperti training untuk karyawannya dengan menebarkan nilai positif, melatih karyawannya untuk saling menghormati dan menhargai satu dengan lainnya, mejelaskan prosedur tentang bagaimana berasuransi, serta memberikan motivasi-motivasi dari ahlinya untuk mencapai target yang diinginkan dan tentunya akan di bimbing sampai sukses.

\section{SARAN}

\section{Saran Akademis}

Peneliti merekomendasikan penelitian kualitatif tentang topik ini untuk melihat sejauh mana pengaruh strategi komunikasi internal dalam menumbuhkan loyalitas karyawan.

\section{Saran Praktis}

Saran peneliti terhadap PRU Eternity adalah diharapkan AM meningkatkan inovasi yang lebih menarik terhadap strategi yang akan dibuat untuk jangka waktu selanjutnya agar strategi yang disusun dapat membangun loyalitas kepada seluruh karyawan serta memancarkan visi dan misi perusahaan yang diinginkan. Langkah-langkah yang diambil harus strategis karena itu mulai dari tahap perencanaan hingga evaluasi harus dilakukan mendalam sesuai dengan kebijakan yang berlaku.

\section{DAFTAR PUSTAKA}

Buku/Bahan Bacaan

Onong, Uchana Efendy. Ilmu Komunikasi Teori dan Praktek. Bandung: PT 
Remaja Rosdakarya, 2005 hal 122

Faules, Don F, Wayne Pace Komunikasi

Organisasi, PT. Remaja

Rosdakarya Bandung. 2005

Mulyana, Deddy, Ilmu Komunikasi Suatu Pengantar, PT. Remaja Rosdakarya, Bandung, 2001

Mulyana, Deddy, Ilmu Komunikasi Suatu Pengantar, PT. Remaja Rosdakarya, Bandung, 2006

Pace, R. Wayne \& Faules, Don F.2005.Komunikasi Organisasi Strategi Meningkatkan Kinerja Perusahaan.

PT.Remaja Rosdakarya. Bandung.

Sukoco, Badri Munir. Manajemen Administrasi Perkantoran Modern. Surabaya:

Erlangga, 2007

Robbins, A. P. Perilaku Organisasi 1 Edisi 10. PT. INDEKS.

Jakarta.2004

Widjaja, H.A.W. Komunikasi dan Hubungan

Masyarakat. Jakarta: Bumi aksara. 2010

Effendy, Onong Uchjana. Ilmu Komunikasi Teori dan Praktek. Bandung: PT
2011 Remaja Rosdakarya.

Sugiyono. Metode Penelitian Kuantitatif Kualitatif dan $R \& D . \quad$ Bandung: Alfabeta. 2017

Muhammad, Arni, Komunikasi Organisasi. Edisi 1

Cet. 13. Jakarta: Bumi Aksara, 2014

Muhammad, Arni, Komunikasi Organisasi, Edisi 1

Cet. 12. Jakarta: PT.

Bumi Aksara 2011

Cangara, Hafied., Pengantar Ilmu

Komunikasi.

Jakarta:

Rajawali Pers.2011

Cangara, Hafied., Pengantar Ilmu

Komunikasi.

Jakarta:

Rajawali Pers.2014

Muslim Basya, Irmulan Sati, Strategi dan Aktivitas

Public Relations. Jakarta: BPP Humas, 2006 hal 28

Frazier Moore, Hubungan Masyarakat Prinsip, Kasus dan Masalah. Bandung: PT Remaja Rosadakarya, 1987

Wasesa, Silih Agung. Strategi Public Relations. Jakarta: PT Gramedia Pustaka Utama, 2005

Ruslan, Rosady. Manajemen Humas dan Manajemen Komunikasi (Konsepsi dan Aplikasi). 
Jakarta: $\quad$ PT Raja Grafindo Persada, 2001

Suryadi, Edi. Strategi Komunikasi

Sebuah Analisis Teori

dan Praktis di Era Global.

Bandung: PT Remaja

Rosdakarya. 2018

Website

http://www.prudential.co.id/corp/pru

dential/ in id/header/aboutus

/index.html diakses pada

Senin, 8 April 2019

www.usepmulyana.files.wordpress.c

om diakses pada Jumat, 29

Maret 2019

https://www.coursehero.com/file/184

70760/04202-038-Hayathun-

Nufus/diakses pada Selasa, 2

April 2019

http://repository.unpas.ac.id/28244/

diakses pada Rabu 27 Maret

2019

Jurnal/Skripsi/Thesis

Oktavia, Tricia, Analisis Kegiatan Komunikasi Internal dalam menumbuhkan Sense

Of Belonging Account Executive PT Indosat Tbk. Depok: FISIP UI, 2014
Martanti, Yenni Maya, Peran Employee Relations Dalam Membangun Loyalitas Karyawan PT Kao Indonesia Jakarta.

Jakarta:

FIKOM MERCU BUANA,

2015

Lie, Ferdyana, Strategi Komunikasi Internal dalam Mensosialisasikan Merger kepada Karyawan (Studi Kasus PT XL Axiata dan PT Axis Telecom Indonesia). Jakarta.

FIKOM UMN, 2015

Oktovina, Yessi Putranti, Strategi Pemasaran Agen PT Prudential Life Assurance dalam meningkatkan Loyalitas Nasabah

Syariah. Jakarta. FEB

UIN, 2015

Defina, Rizka, Kegiatan

Komunikasi Internal dalam meningkatkan Sense

Of Belonging

Karyawan di PT Alpa Scorpii Medan, UMS, 2018 